\title{
Prostaglandins and the gastric epithelium: effects of misoprostol on gastric epithelial cell proliferation in the dog
}

\author{
R A GOODLAD, A J MADGWICK, M R MOFFATT, S LEVIN, J L ALLEN, \\ AND N A WRIGHT \\ From the Cancer Research Campaign Cell Proliferation Unit, Department of Histopathology, Royal \\ Postgraduate Medical School, Hammersmith Hospital, Ducane Road, London and Searle Research \\ and Development, G D Searle and Co, Skokie, Illinois, USA
}

SUMmary The effects of the methyl ester analogue of prostaglandin $E_{1}$, misoprostol, on gastric epithelial cell proliferation were investigated in six dogs given $300 \mu \mathrm{g} / \mathrm{kg} / \mathrm{day}$ of misoprostol orally for 11 weeks and in six control dogs given placebo for 11 weeks. Misoprostol treatment resulted in a $36 \%$ increase in stomach weight $(\mathbf{p}<0 \cdot 01)$ and a $30 \%$ increase in the length (measured as the cell column count from the base/neck junction to the surface) of the fundic gastric glands $(p<0 \cdot 01)$. This mucosal hyperplasia was predominantly caused by enlargement of the foveolar region of the gland, with little change occurring in the neck or in the isthmus. The hyperplasia was the result of an increased number of mitotic $(p<0.01)$ and DNA synthesising cells $(p<0.05)$ in each gastric gland, which resulted in a significant increase in the gland cell production rate, from $22 \cdot 5$ to $42 \cdot 6$ cells per gland per day $(p<0 \cdot 05)$.

Prostaglandins are short lived derivatives of essential fatty acids which act as chemical messengers at or near their site of production. Longer lived stable synthetic analogues of the prostaglandins have now been developed, providing the opportunity for their use in the exogenous treatment of pathological conditions. There is evidence that a deficiency in prostaglandin synthesis is implicated in peptic ulcer disease.' Prostaglandins (including the synthetic analogue of prostaglandin $E_{1}$, misoprostol) have the ability to protect the gastric mucosa from the adverse effects of a variety of noxious agents..$^{2-5}$ Prostaglandins and their analogues are also potent inhibitors of gastric acid secretion, and consequently have considerable potential as anti-ulcer agents. - $^{-10}$ Misoprostol has several effects on the intestinal mucosa, which include increasing bicarbonate secretion, ${ }^{11}$ mucus production, ${ }^{12}$ and mucosal mass..$^{13}$

Address for correspondence: Dr R A Goodlad, Imperial Cancer Research Fund Unit, Dept of Histopathology, Royal Postgraduate Medical School, Hammersmith Hospital, Ducane Road, London W12 0HS.

Accepted for publication 21 July 1988.
While some investigators have found that misoprostol significantly stimulated mucosal DNA synthesis $^{14}$ and cell proliferation, ${ }^{15}$ others have reported no proliferative effects ${ }^{16}$ or even decreased proliferative indices, ${ }^{17}$ causing them to suggest that the gastric hypertrophy observed after longterm prostaglandin administration was the result of decreased cell loss rather than increased proliferation. ${ }^{17-19}$ There are difficulties in the interpretation of the data from the various studies as different species and different techniques were used. In addition the study of intestinal epithelial cell proliferation has also been bedevilled by the use of techniques whose limitations may not be fully understood; especially those based on the gross uptake of tritiated thymidine, as this can be influenced by a variety of factors other than the rate of entry of cells into DNA synthesis. ${ }^{21}$ State measures, such as proliferative indices can also be misleading, especially if there is a concomitant increase in the denominator. The present paper describes a detailed kinetic study of the effects of misoprostol on canine gastric epithelial cell 
proliferation and cell production. A relatively high dose of misoprostol was used in order to facilitate the accurate quantification of the mucosal hyperplasia. The dogs were kept on the treatment for a long period of time so that they would be in a "steady state" with regard to cell production and cell loss. The effects of misoprostol on cell migration, transit time, and gastric morphology will be described in subsequent papers.

\section{Methods}

EXPERIMENTAL PLAN

Six dogs were given a gelatin capsule containing misoprostol once a day for 77 days $(300 \mu \mathrm{g} / \mathrm{kg} / \mathrm{day})$ while six (control) dogs were given the vehicle alone. On the last day the dogs were injected iv with 0.25 $\mathrm{mCi} / \mathrm{kg}$ of tritiated thymidine and killed one hour later. The digestive tract was completely removed and the stomach opened along its greater curvature, rinsed, blotted, and weighed. The stomachs were weighed and samples of fundic and antral gastric mucosa were fixed in Carnoy's fluid and then stored in $70 \%$ ethanol. The 12 dogs referenced here were part of a larger study in which there were 30 control and 30 misoprostol treated animals. Other aspects of the study will be reported separately.

\section{ANIMALS}

Male beagle dogs, eight to 10 months old and weighing $11.2-14.9 \mathrm{~kg}$ were used. They were individually housed in environmentally controlled rooms, with a 12 hour light and 12 hour dark cycle. Purina certified canine diet was provided three hours after the test agent had been administered and was available for two hours. Tap water was available ad libitum. The antemortem part of this study was carried out at Hazleton Laboratories America Inc, 3301 Kinsman Blvd, Madison, Wisconsin, USA.

\section{HISTOLOGY}

Fundic mucosa was embedded in wax and alternate 4 micron sections cut and mounted. Autoradiographs were prepared by the dipping method $^{21}$ using Ilford K2 emulsion (Ilford Ltd, Rajar Works, Town Lane, Knutsford, Cheshire, UK). After four weeks exposure, the autoradiographs were developed in Kodak D19b, fixed and stained with haematoxylin and eosin.

DATA GATHERING FROM AUTORADIOGRAPHS Slides were examined systematically for well orientated glands (sectioned along the axis of the gland's lumen) see Figure 1. The base/neck junction was defined as the location of the most basal mucous neck

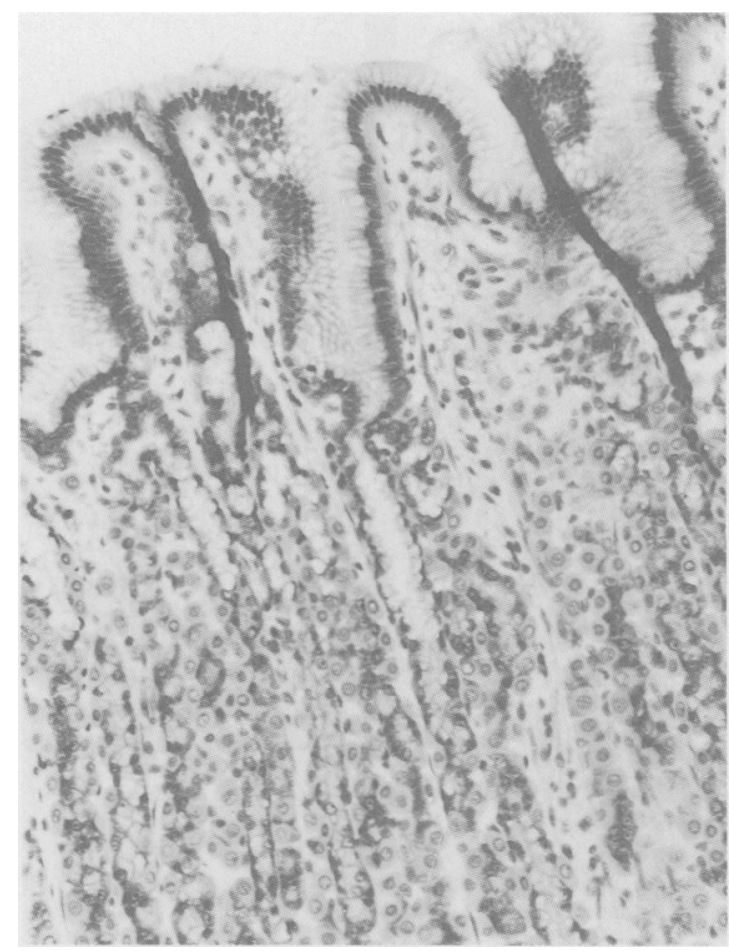

Fig. 1 Photomicrograph of mucosa from the gastric fundus showing a gland with its neck, isthmus and foveolus apically sectioned. The neck region (between the arrows) is defined by the presence of the cresent shaped mucus neck cell nuclei. The isthmus/foveolus junction was defined by the uppermost parietal cell, recognisable by their large nuclei and eosinophilic cytoplasm (fried egg like appearance).

cell,,$^{22}$ and this was designated position 1 . The gland was then scored, by recording the location of labelled and mitotic cells up to the top of the foveolus. The gland length was thus defined as the column count from the base/neck junction to the mucosal surface.

The background threshold level of radioactivity was determined by a technique of analysis of outliers ${ }^{23}$ and a threshold level of four silver grains per nucleus adopted; that is for a nucleus to be scored as labelled it must have had one or more grains directly overlying its nucleus. For a nucleus to qualify for mitotic scoring the nuclear envelope must have been absent and the chromatin starting to condense; thus early prophase or indistinct hyperchromatic nuclei were excluded. Labelling and mitotic data were expressed as the respective indices (number of labelled or mitotic cells per 100 gland cells) and as the number of dividing cells per gland column. The mitotic/labelled cell per gland data were then converted into gland cell production rates - that is, the number of cells produced per gland per day (assum- 


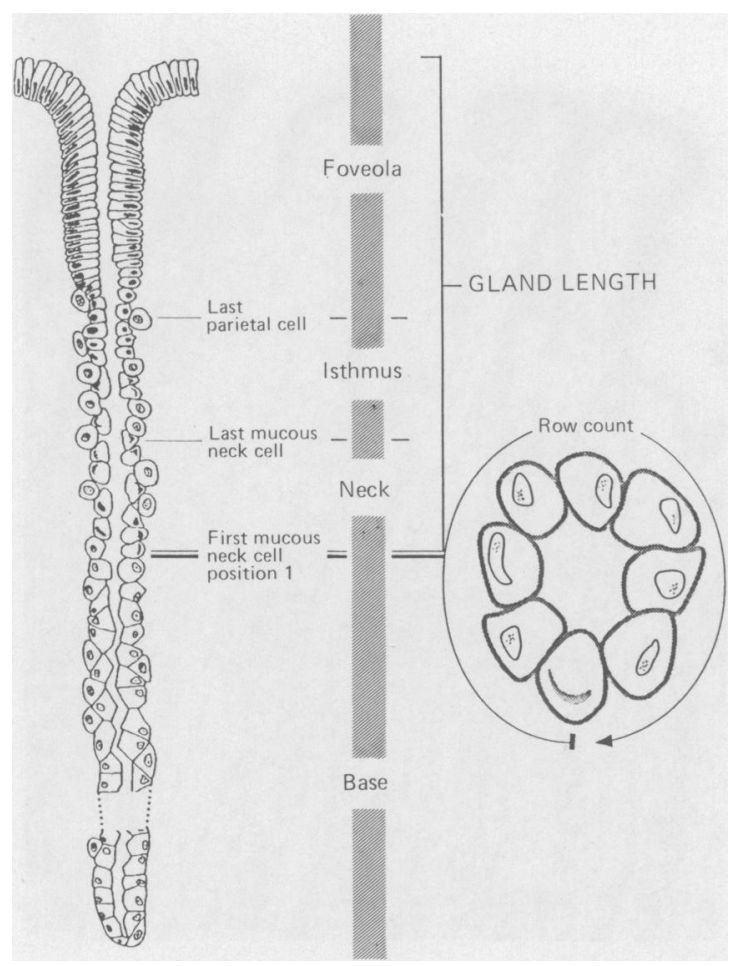

Fig. 2 Diagram of a gland from the gastric fundus. Cilands were scored from the hase/neck junction which was demarcated by the most basal mucous neck cell. The row count was determined in well oriented glands cut in cross sectiont.

ing a mitotic duration of one hour and a S-phase duration of eight hours). Because the production rates were based on the mitotic/labelling data per gland, the statistical probabilities were the same.

Two 'marker' cell positions were also recorded, namely, the last mucous neck cell (neck/isthmus junction; which is the zero point used by Willems et al, ${ }^{2+}$ and the position of the last parietal cell (isthmus/ foveolus junction) (Fig. 2).

For the determination of the row count Alcian blue/periodic acid Schiff stained sections were examined and the number of cells in the circumference of well oriented glands cut in cross section (parallel to the mucosal surface) counted (Fig. 2). Glands were only scored if sectioned through the neck region (that is if mucous neck cells were present).

\section{Results}

There was no change in the body weight of the two groups of animals, but a $36 \%$ increase in the wet weight of the stomach of the misoprostol treated
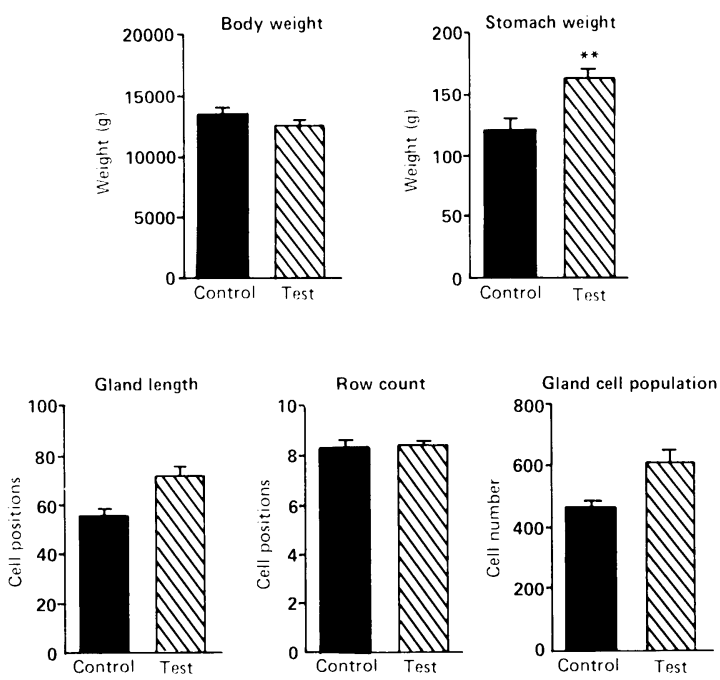

Fig. 3 Effects of misoprostol on body and stomach weight. Also shown are the gland length (from base/neck junction to foveolar surface), gland diameter or row count and the product of these last two parameters which is the gland cell population. There were six animals per group.

* = significantly different than control group $(p<0 .(05)$;

$*^{*}=$ significantly different than control group $\left.(p<0) \cdot() 1\right)$.

group $(p=0.0068)$ was observed (Fig. 3). No significant difference in body weight or food consumption was noted.

The gland length (cell column count from the base/ neck junction to the mucosal surface), was increased by $30 \%(p=0.0042)$ in the misoprostol treated group. There was no change in the gland row count $($ control $=8 \cdot 357 \pm() \cdot 213$ and test $=8 \cdot 4() 8 \pm 0 \cdot 15)$. The gland cell population, defined as the product of gland column and row counts, consequently increased by $32 \%$ in the misoprostol treated group $(\mathrm{p}=0.008)$ (Fig. 3).

The location of labelled and mitotic cells approximated to a normal distribution $(\mathrm{p}<0.05$ by normal scores test, Table). Very little labelling or mitosis was

Table I)escription (cell positions) of the distribution of labelled and mitotic cells in the gastric gland (from the basel neck junction to the luminal surface) of control and misoprostol treated dogs

\begin{tabular}{|c|c|c|c|c|}
\hline & \multicolumn{2}{|c|}{ Control } & \multicolumn{2}{|l|}{ Test } \\
\hline & Me'an & SEM & Me'an & $S E M$ \\
\hline Mean of labelling distribution & $23 \cdot 19$ & $1.9(1)$ & $23 \cdot 66$ & $1 \cdot 8(0)$ \\
\hline Median of labelling distribution & $22 \cdot 36$ & & $23 \cdot 66$ & \\
\hline Neck/isthmus junction & $1+\cdot 02$ & $1 \cdot 37$ & $14 \cdot 15$ & $1 \cdot(19)$ \\
\hline Isthmus/foveolus junction & 26.94 & $1 \cdot 6.3$ & $25 \cdot 1) 5$ & $1 \cdot 88$ \\
\hline Mean mitotic distribution & 24.51 & $1 \cdot 17$ & $25 \cdot 52$ & 0.92 \\
\hline Median mitotic distribution & $23 \cdot(x)$ & & $26 \cdot(x)$ & \\
\hline
\end{tabular}



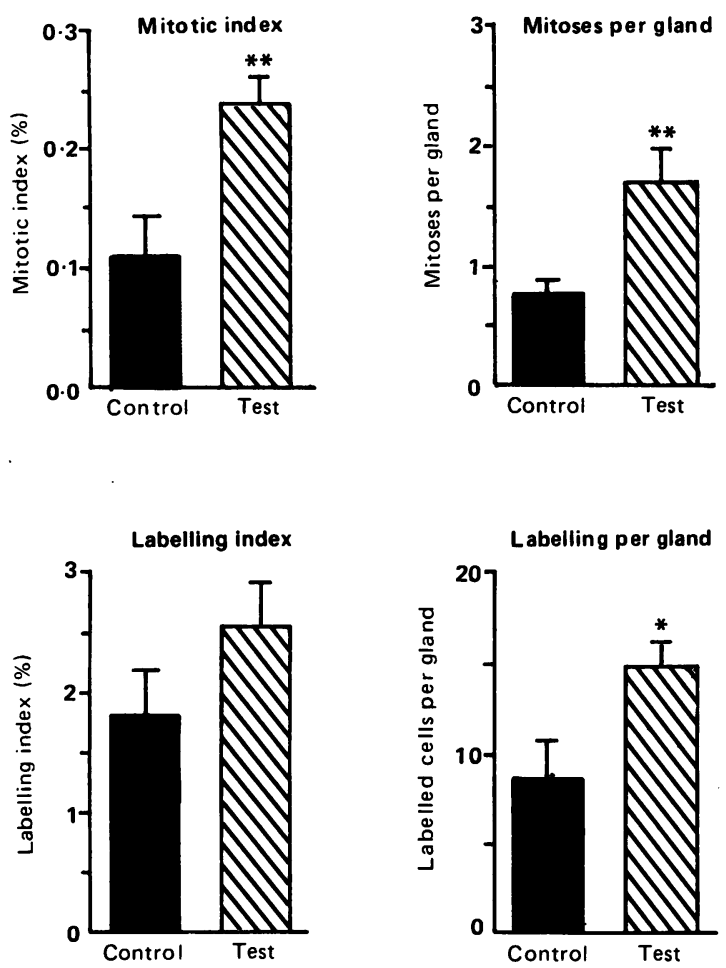

Fig. 4 Mitotic and labelling indices of the control and the misoprostol treated groups and the number of mitotic and labelled cells per gland. There were six animals per group. *=significantly different than control group $(p<0.05)$;

$* *=$ significantly different than control group $(p<0.01)$.

seen in the base of the gland. The similarities of the mean and the median values for each group further indicate the symmetry of the distributions, There was little difference in the position of the junction markers (last mucous neck and last parietal cells) with misoprostol treatment; thus the expansion in gland length must have occurred in the foveolus.

The labelling and mitotic data are presented in Figure 4 . The mitotic index increased by $117 \%$ in the test group $(p=0 \cdot 0098)$, but while the labelling index rose by $41 \%$ this was not statistically significant. Figure 4, however, also shows that the number of mitotic or labelled cells per gland however had increased by $118 \%(p=0.003)$ and by $73 \%(p=0.025)$ respectively. This data were then converted into gland cell production rates which are shown in Figure 5 .

\section{Discussion}

The increase in gastric mucosal weight associated with misoprostol treatment was very similar in its extent to the observed increase in gland cell column

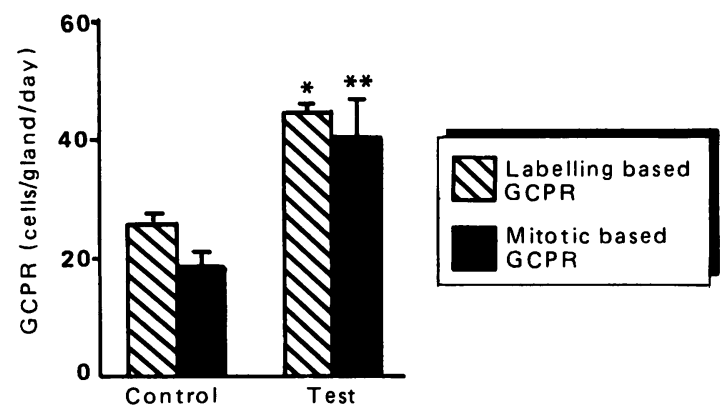

Fig. 5 Effects of misoprostol on the daily production of cells by the fundic gastric gland (GCRP) either calculated using the mitotic data or the labelling data. *=significantly different than control group $(p<0.05) ;{ }^{* *}=$ significantly different than control group $(p<0.01)$.

count. There was no change in the position of the last mucous neck cell and the last parietal cell which demark the neck/isthmus and isthmus/foveolus respectively; thus the increase in gland length can be attributed to an increase in the number of surface mucous cells in the foveolus. It can thus be concluded that the increased stomach weight was predominantly due to hyperplasia rather than hypertrophy.

Mitotic and labelling indices are measures of state, not rate, and as such can be misleading, especially if associated with concomitant changes in cell population size. This was indeed the case in the present investigation, as a casual inspection of the labelling index (labelled cells per 100 gland cells) would suggest that there was no significant proliferative effect. When the number of labelled cells per gland and the gland cell production rate were considered, however, the difference between the treated and control animals became apparent. The importance of the correct choice (and use) of method cannot be overemphasised. ${ }^{25}$ The difficulties in obtaining well orientated glands in the tissue available from gastric biopsies in man has persuaded some workers ${ }^{17}$ that they should confine their quantification to the gastric foveolus; but most cell division occurs in the neck and isthmus. Thus an expanded foveolus population would effectively 'dilute' the labelling index obtained, and yield results which are at odds with other investigations. ${ }^{26}$

There was little difference in the pattern of distribution of labelled cells within the gland between the two groups, which suggests that the increased cell production either occurred through the resting phase $\left(G_{1}\right)$ decreasing or via a general shortening of the cell division cycle time. The usual kinetic response is a decreased duration of the $G_{1}$ resting phase rather than an alteration of the DNA synthesis (S) phase, the postsynthetic gap $G_{2}$, or the mitotic $(M)$ phase..$^{.5}$ If the cell cycle time or the duration of the mitotic or 
of the DNA synthesis phases had decreased, our estimates of the gland cell production rate would in fact be underestimates.

The agreement between the mitotic and labelling based estimates of gland cell production was quite good, the differences observed could either be explained by experimental variation, by the rigorous definition of mitosis used, or by the presence of a diurnal rhythm of cell proliferation. ${ }^{25}$

Raised rates of gastric epithelial cell proliferation and the resultant increase in surface mucous cell population should increase the stomach's ability to withstand damage and to repair itself in several ways in addition to the mechanical protection afforded by increased mucosal mass. One of the first responses to epithelial damage is a rapid migration of epithelial cells to re-epithelialise the injured area; ${ }^{27}$ an increased epithelial population might aid this process. The surface mucous cells also secrete considerable quantities of mucous and of bicarbonate, both of which have obvious implications for mucosal protection." mainly occurred in the foveolar region, as the position of the uppermost parictal cell did not change (isthmus/foveolus junction); so that the relative proportion of the gland devoted to acid secretion would have been decreased, which should also shift the balance between damage and protection towards the latter.

In conclusion, misoprostol effectively elicits a hyperplastic response in the gastric mucosa resulting in a significantly increased gland cell population, with most of the increase occurring in the mucous and bicarbonate secreting surface mucous cell (foveolar) cells.

We would like to thank Mrs Y E Price for the histological preparations and autoradiographs.

\section{References}

I Pugh S. Prostaglandins, is deficiency a pathophysiological influence in peptic ulcer discase. (; Futures 1986: 1: 11-3.

2 Jacobson ED. Direct and adaptive cytoprotection. Dig Dis Sci 1986; 31: 28S-31S.

3 Lacy ER. Fiffects of absolute ethanol, misoprostol, cimetidine, and phosphate buffer on the morphology of rat gastric mucosac. Dig Dis Sci 1986; 31: 101S-7S.

4 Liss RH. Letourncau RJ, Schepis JP. Evaluation of cytoprotection against ethanol-induced injury in gastric mucosa pretreated with misoprostol, cimetidine or placebo. Dig Dis $S_{c} i$ 1986; 31: 108S-14S.

5 Yeomans ND. The protective effects of prostaglandins in the human gastrointestinal tract. Therapeutics Today. 1986: 5 (suppl): 19-25.

6 Herting RL. Overview of misoprostol clinical experience. Dig Dis Sci 1986: 31: 47S-54S.
7 Rachmilewitz D, Chapman JW, Nicholson PA. A multicentre international controlled comparison of two dosage regimens of misoprostol with cimetidine in treatment of gastric ulcer in outpatients. Dig Dis $S_{C i}$ 1986; 31: 75S-80S.

8 Bright-Asare P, Sontag SJ, Gould RJ, Brand DL, Roufail WM. Efficacy of misoprostol (twice daily dosage) in acute healing of duodenal ulcer. A multicentre double-blind controlled trial. Dig Dis Sci 1986; 31: $63 \mathrm{~S}-67 \mathrm{~S}$.

9 Hawkey CJ, Rampton DS. Prostaglandins and the gastrointestinal mucosa: are they important in its function, disease or treatment? Gastroenterology 1985; 89: $1162-88$.

10 Hawkey CJ, Walt RP. Prostaglandins for peptic ulcer, a promise unfulfilled. Lancet 1986; ii: 1084-8.

11 Smedfors B, Johansson C. Stimulation of duodenal bicarbonate secretion by misoprostol. Dig Dis Sci 1986; 31: 96S-100S.

12 Wilson DE, Quadros E, Rajapaksa T, Adams A, Noar M. Effects of misoprostol on gastric acid and mucous secretion in man. Dig Dis Sci 1986; 31: 126S-9S.

13 Dembinski A, Konturek SJ. Effects of E, F, and I series prostaglandins and analogues on growth of gastroduodenal mucosa and pancreas. Am J Physiol 1985; 248: $170-5$.

14 Assad RT, Dodd DC, Dajani EZ. Effects of misoprostol on DNA synthesis of canine fundic mucosa. Gastroenterology 1985; 88: 1310.

15 Assad RT, Dodd DC. Dajani EZ. Effects of misoprostol (prostaglandin $E_{1}$ analoguc) on epithelial proliferation of canine fundic mucosa. Gastroenterology 1985; 88: 1310 .

16 Fich A, Arber N, Sestieri M, Zajicek G, Rachmilewitz $D$. Effect of misoprostol and cimetidine on gastric cell labelling index. (iastroenterology 1985; 89: 57-61.

17 Arber N, Fich A, Zajicek G, Rachmilewitz D. Effect of misoprostol and cimetidine on human gastric cell turnover. Gastroenterology 1985; 88: 1710.

18 Halter F, Baumgartner A, Koelz HR, Reinhart WH. Effect of prostaglandins on the adult rat stomach and intestine. Gut 1987; 28: S1 139-41.

19 Uribe A, Tribukait B, Johansson C. Cell cycle distribution of proliferative and functional cells of the rat jejunum after treatment with oral $\mathrm{E}_{2}$ prostaglandins. Scand J Gastroenterol 1987; 22: 177-84.

20 Goodlad RA, Wright NA. Quantitative studies on epithelial replacement in the gut. In: Titchen TA. ed. Techniques in the life sciences. Techniques in digestive physiology. Ireland: Elsevier Biomedical Press, 1982: 212/1-212/23.

21 Rogers AW. Techniques of autoradiography. Amsterdam: Elsevier, 1979.

22 Goodlad RA, Wright NA. The gastric epithelium. GI Futures 1986; 1: 16-9.

23 Barnett V, Lewis J. Analysis of the outliers of a Poisson distribution. Chichester: John Wiley, 1984.

24 Willems G, Galand P, Chretien J. Autoradiographic studies on cell population kinetics in dog gastric and rectal mucosa. A comparison between in vivo and in vitro methods. Lab Invest 1970; 23: 635-9.

25 Wright NA. Alison M. The biology of epithelial cell populations. Oxford: Clarendon Press, vol 1: 1984. 
26 Smedley F, Wastell L. Gastric cell turnover. Gastroenterology 1986; 86: 265.

27 Lacy ER, Ito S. Ethanol induced injury to the superficial rat gastric epithelium: a study of damage and rapid repair. In: Allen A, Flemstrom G, Gardner A, Silen W. Turnberg LA, eds. Mechanisms of mucosal protection in the upper gastrointestinal tract. New York: Raven Press, 1984: 49-56.

28 Allen $\mathrm{A}$. The mucus-bicarbonate barrier and gastroduodenal protection. GI futures 1986; 1: 6-8.

29 Helander HF. The cells of the gastric mucosa. Int Re' Cytol 1981; 70: 217-90. 